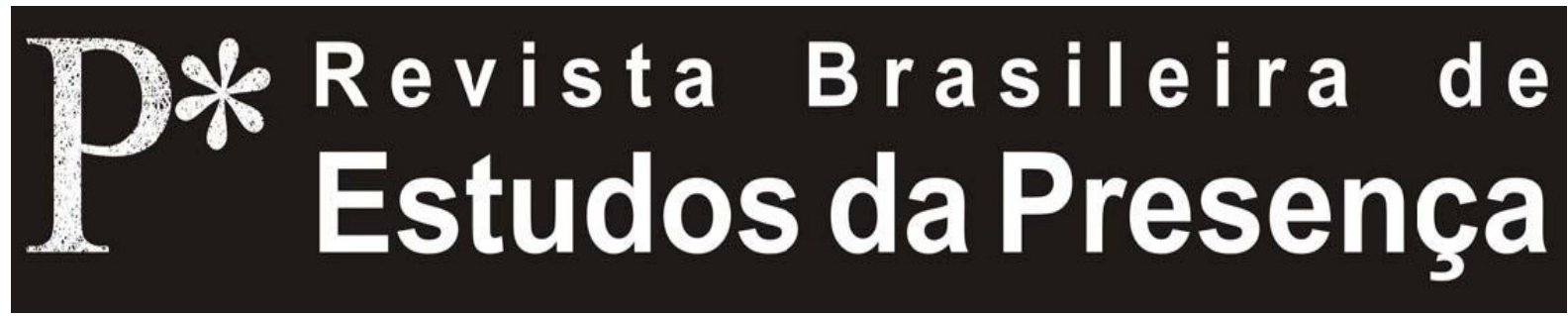

DOI - http://dx.doi.org/10.1590/2237-266039158

ISSN 2237-2660

\title{
A Fabricação do Teatro: questões e paradoxos
}

\author{
Josette Féral \\ Université Paris 3 Sorbonne Nouvelle - Paris, França
}

RESUMO - A Fabricaçáo do Teatro: questóes e paradoxos - Este texto apresenta algumas questóes relativas à Genética Teatral, se debruçando, notadamente, sobre a análise dos processos de criação. A autora propóe o conceito de traço, mais do que o de brouillon adotado anteriormente, para melhor compreender a análise genética da encenação. Esse tipo de análise toma em conta todo o processo anterior a apresentação. A reflexão problematiza os conceitos de practice as research e de art-based research como ferramentas que permitem um movimento para outros campos da genética. E, ainda mais importante, o texto propóe restringir o domínio da ação da Genética Teatral ao processo estrito de criação a fim de tornar a análise mais eficaz e mais pertinente.

Palavras-chave: Processos de Criação. Genética Teatral. Traços. Arquivos. Encenação Teatral.

ABSTRACT - The Production of Theater: stakes and paradoxes - This text presents issues of Theatrical Genetics, in particular, in its relation with the analysis of living processes of creation. The text proposes the concept of trace - in its production and disappearance, both typical of the theatrical process -, in order to understand the genetic analysis of staging, taking into consideration the entire process prior to the presentation and, at the same time, considering the presentation as part of this process. The text proposes to restrict the field of action of Theatrical Genetics to the analysis of creative processes only to better empower it.

Keywords: Creative Processes. Theatrical Genetics. Traces. Archives. Theatrical Staging.

RÉSUMÉ - La Fabrique de Théâtre: enjeux et paradoxes - Ce texte présente quelques questions relatives à la génétique théâtrale portant, notamment, sur l'analyse des processus de création. L'auteur propose le concept de trace, plutôt que celui de brouillon adopté antérieurement pour mieux comprendre l'analyse génétique de la mise en scène, analyse qui prend en compte tout le processus antérieur à la représentation. La réflexion menée ici ouvre sur les concepts de practice as research et de art-based research comme outils permettant une excursion vers d'autres champs de la génétique. Plus importan encore, le texte propose de restreindre le domaine d'action de la génétique théâtrale aux stricts processus de création afin d'en rendre l'analyse plus efficace et plus pertinente.

Mots-clés: Processus de Création. Génétique Théâtrale. Traces. Archives. Mise en Scène. 
Todo espetáculo que é estudado, a partir de uma análise, constitui apenas um momento de um processo que dever ser incessantemente reafirmado. Ele se encontra precisamente na interface entre as etapas passadas que podem ser objeto de um estudo sistemático a partir de documentos existentes ou sessóes de trabalho e a preservação da obra como objeto vivo percebido pelo espectador. Por um lado, as observaçóes se relacionam ao trabalho genealógico de preparação da obra (direção de atores, trabalho com aqueles que criam os elementos sonoros ou plásticos, pesquisa feita pelo ator sobre a sua partitura, exploraçóes sobre o texto, o personagem, a narrativa; hesitaçóes, cortes, escolhas); por outro lado, elas procuram refletir a experiência dos espectadores, especialmente no caso de certas formas participativas, nas quais essas reaçôes são constitutivas do espetáculo.

Uma vez que a necessidade da relaçáo com a obra em processo é reconhecida, como abordar o seu estudo? Qual é a importância a ser dada ao campo genético? Vinte anos mais tarde, diferenças se impóem e as questóes metodológicas ainda se colocam, mesmo se alguns avanços reais na área podem ser registrados. Nós apresentaremos alguns desses avanços e ressaltaremos algumas das novas questóes dessa área de pesquisa. Trata-se aqui mais de uma reflexão em progresso do que um percurso com respostas já elaboradas.

\section{Algumas Consideraçóes Preliminares}

As reflexóes que seguem me acompanham além da pura análise dos processos de criação ligados a um espetáculo, a um artista ou a uma estética. Com efeito, o que importa nesse percurso, além da observação de fenômenos vindos da prática (e observados em ensaios, por exemplo), é a maneira de colocar indicadores nestes campos de estudo que são a genética da encenação e, mais especificamente, o processo de criação? O que é necessário integrar a eles? O que precisa ser excluído? Como navegar neles? Eu me esforçarei para estabelecer uma diferença entre essas duas áreas de pesquisa que certamente apresentam ligaçôes, mas que náo são, em minha opiniáo, inteiramente sobreponíveis ${ }^{1}$.

Eu tentarei tratar, também, de maneira periférica, a questão da própria emergência desse campo de estudo no panorama das pesquisas atuais sobre o teatro, e do que ele nos diz sobre as relaçóes entre pesquisa e prática artística, particularmente na área de estudos que nossos colegas anglo-saxóes denominam como practice as research e art-based research, duas expressões que não têm o mesmo significado. 


\section{Um Aleatório Assumido Livremente}

A crítica genética coloca como hipótese inicial, escreve PierreMarc de Biasi, que a obra "[...] é o efeito das suas metamorfoses e contém a memória da sua própria gênese" (De Biasi, 2000, p. 9). Ela seria, então, fundada sobre a premissa de que a obra é o efeito de um trabalho, e de um trabalho que deixa traços, resquícios que se depositam na obra sob a forma do espetáculo terminado e fora da obra sob a forma de documentos, rascunhos, anotaçóes, declaraçóes diversas que constituem a memória da obra que está sendo criada.

Pode-se dizer que todos esses traços constituem arquivos, o que é uma questão interessante e cuja resposta não é uma evidência absoluta, sendo o estatuto do arquivo um estatuto bem específico?

Ora, e esta será minha primeira observação, o estatuto desses traços muda de acordo com as épocas. O que quero dizer com isso é que o estudo dos traços de um espetáculo não reflete uma preocupação que seja própria ou única à nossa época. De fato, os vestígios das formas espetaculares existem desde a origem da arte e particularmente $\mathrm{da}$ arte teatral. Esses vestígios (documentos, narrativas, arquivos, esboços, quadros, descriçóes, procedimentos) são objeto de estudos há muito tempo, permitindo a análise não somente de espetáculos para restituir suas ideias, mas, também, observando o fazer do artista (em especial do cenógrafo e do ator, ou mesmo do técnico). Portanto, é a performatividade da obra que é objeto de análise e, de maneira periférica, a sua fabricação. As análises mostram que a fronteira entre a utilização de traços para compreender melhor um espetáculo terminado e para compreender melhor os processos de criação desse mesmo espetáculo são bem estreitas, e a utilização dos traços do espetáculo durante a criação, se não frequente, é, ao menos, presente.

Quando certos atores do século XIX se escondem na caixa do ponto para apreender as técnicas de jogo do ator, nós já estávamos diante da observação de um processo de criação. A diferença maior, no entanto, é que essa observaçáo não tem por objetivo compreender o processo da criação da obra, mas poder fazer uso de uma técnica de atuaçáo e imitá-la quando necessário. Contanto que a observaçáo do nosso aspirante a ator na caixa do ponto seja registrada, escrita, contada, memorizada, nós poderíamos dizer que ela deixa traços e constitui, sem sombra de dúvida, o exemplo de uma forma rudimentar de investigação de um processo de criação.

Pesquisadores estudam há tempos a natureza desses traços deixados pelo espetáculo e, antes dele, pelo processo de feitura do 
espetáculo. Nós os chamávamos em outros lugares de esboços (textuais, visuais, sonoros), mas seria mais exato, penso, incluí-los hoje sob uma denominação mais geral, que eu chamaria de traços.

O ponto importante da nossa reflexão é que os traços existem e que a imensa rede que eles constituem pode dar a impressão que as premissas dos estudos genéticos já estão colocadas há muito tempo. Em todo caso, essa rede póe em relevo o fato de que a utilização de traços de espetáculos para compreender melhor as obras é uma constante na crítica teatral desde as origens. Isso ressalta, também, caso necessário, que o interesse pelos processos de criação não é algo recente, mesmo se os séculos passados o designaram de outra forma. Temos a esse respeito quatro observaçóes.

\section{I}

Por que falar de traços ao invés de arquivos? Seria interessante abordar a diferença entre traço e arquivo. Todo traço não é necessariamente um arquivo? $\mathrm{O}$ arquivo possui uma história remota, já que o conceito ocidental de arquivo surge nos Gregos há pelo menos vinte e seis ou vinte e sete séculos (conforme a palavra Arkhè). Todos os povos antigos minimamente civilizados possuíam arquivos (os assírios, os chineses, os egípcios). Na França, os arquivos nacionais foram criados a partir de 1789 . Outros países seguiram gradualmente, o que náo impedia a existência de arquivos por toda parte e há muito tempo (em castelos, nos tabelionatos, nos monastérios, nos tribunais). No Quebec, os arquivos nacionais datam apenas dos anos 1960. A história séria, vista como uma disciplina baseada em arquivos, começou logo depois. Michelet foi, sem dúvida, um dos primeiros a considerar a história como ciência - e não mais como literatura -, particularmente, em função dos arquivos. Então, seria interessante estudar o que o conceito de arquivo traz para a pesquisa teatral como aprofundamento e legitimidade e, também, como institucionalização.

O conceito de traço, por sua vez, é mais recente. Ele parece mais leve também, mais difícil de definir. Ele é de diferentes naturezas, tanto real quanto virtual. Ele data (no sentido moderno do termo) a Freud (os traços mnésicos), que buscou sua inspiração nos arqueólogos que tinham legitimado a seriedade da sua área de exploraçáo por volta da metade do século XIX, procurando reunir os traços escritos da antiguidade (de onde vem a epigrafia e a Academia das Inscriçóes). Foi, entáo, se inspirando nos arqueólogos e, mais precisamente, na 
egiptologia, pela qual era apaixonado, que Freud utilizou a noçáo de traços. Haveria um grande trabalho a realizar sobre essa questáo do arquivo.

A palavra traço, e o conceito que ela cobre, me parecem mais de acordo com os modos de trabalho atuais. Ela é múltipla, polissêmica, exprime bem a diversidade de natureza e de origem dos traços possíveis. Eles podem ser, por exemplo, tanto sonoros quanto gráficos, tanto escritos quanto mnésicos, tanto virtuais quanto tangíveis, refletindo a multiplicidade dos dados que podem ser reunidos em torno da criaçáo de um espetáculo. $\mathrm{O}$ aspecto mais importante dessa classificação é a possibilidade de se ter traços virtuais ou invisíveis ou, ainda, ausentes. Com efeito, esse é um dos pontos fundamentais, me parece, que diferencia a genética literária da genética teatral.

II

Isso me leva a um segundo ponto importante, a natureza desses traços é fundamental. De fato, eles não têm a mesma importância. Alguns projetos de cenário de Pierre-Adrien Pâris (1700-1800) e os esboços que Wilson realiza como croquis preliminares às suas criaçóes não têm nem a mesma densidade de informação nem o mesmo status, mesmo se os dois permitem uma melhor compreensão dos espetáculos aos quais eles deram origem. Alguns desses traços são naturalmente muito ricos em informação, outros são esboços que apontam em uma direção e pedem a criatividade da cena para serem seguidos. Eles sugerem futuros desenvolvimentos, deixam lugar à evolução da criação ou ao imaginário. Eu diria que alguns são saturados e estão mais perto do espetáculo terminado, ao passo que outros continuam lacunares e configuram pistas que os diferentes criadores do espetáculo são convidados a seguir ou pelas quais eles podem ser inspirados. Os traços mostram claramente as etapas de um processo e atraem outros traços. Eles registram um percurso artístico, destacando uma etapa da criação da obra.

\section{III}

Meu terceiro ponto visa a destacar que, se outrora os traços não eram necessariamente destinados a serem preservados, hoje a fabricação de traços é um sinal dos tempos que deve ser levado em consideração, pois ela pode influenciar sua análise. Pois se antes era o acaso, a coleta, a pesquisa que nos permitia encontrar traços do espetáculo, reconstituí-los, criar diálogos entre eles, hoje em dia 
esses traços são, às vezes, tornados públicos bastante rápido, quando eles não são publicados pouco tempo depois do espetáculo ou até ao mesmo tempo que as apresentaçôes: anotaçóes do diretor, cadernos dos assistentes ${ }^{2}$. Às vezes, alguns detalhes podem até mesmo acompanhar o programa do espetáculo, revelando que o olhar se desviou definitivamente do espetáculo para a obra em criação. Diretores, atores, assistentes de direção, criador de som ou criador de vídeo são mais do que nunca levados náo somente a preservar os traços dos seus trabalhos (por isso o conceito de esboço não me parece mais exato), mas a divulgá-los. $\mathrm{O}$ mesmo acontece com os vídeos, que são integralmente acessíveis.

\section{IV}

Ora, esses traços são problemáticos na medida em que eles atenuam um fato importante, de que os traços teatrais náo podem funcionar realmente como esboços textuais. De fato, se os esboços são rasurados, se sobrepóem, se substituem, se deslocam no texto, eles não apagam o texto de início - ou o texto final - que continua inteiro e ileso; de modo contrário, a Genética Teatral se baseia no desaparecimento dos traços, traços ausentes, apagados, rasurados ${ }^{3}$.

De fato, contrariamente aos esboços textuais, os esboços de teatro são fundamentalmente construídos sobre uma lacuna. E a observação de Pierre-Marc de Biasi sobre a crítica genética, mencionada anteriormente, não me parece exata (a obra "é o efeito das suas metamorfoses e contém a memória da sua própria gênese" (De Biasi, 2000, p. 9)), a menos que o autor esteja falando, aqui, como um psicanalista, de uma memória fragmentária, lacunar.

Se a obra é de fato "o efeito de suas metamorfoses", ela não contém, no entanto, toda a memória da sua própria gênese, já que o espetáculo se faz, é claro, por caminhos explícitos e facilmente registráveis na obra terminada (gestual, cenografia, interpretação, figurinos, esboços), mas ele se faz, também, e, sobretudo, por eliminação, por supressão e atenuação (desaparecimento) dos traços. Da mesma forma, com muita frequência, o trabalho do diretor consiste em escolher entre aquilo que o ator propõe. Ele retém, é claro, mas ele também apaga muito, elimina, escolhe. Esse é na verdade seu papel principal a fim de dar ao espetáculo a eficácia e a estética desejadas. Então, as correçóes, as eliminaçôes, as supressóes parecem táo importantes a analisar quanto o que fica e o que permanece na obra final. É assim que, em uma encenação de Urfaust, de Denis 
Marleau, Andreas Yandl (2001) estudou os diferentes deslocamentos de um crânio que transitou em lugares diferentes do palco antes de ser definitivamente retirado da encenaçáo como acessório. Ora, essa supressão me parece tão eloquente quanto o surgimento, por sua vez, de outros elementos que foram privilegiados por Marleau para evocar os rituais satânicos no espetáculo ${ }^{4}$; e a análise genética deveria levar isso em consideração.

Esse é um ponto importante e frequentemente negligenciado. Fazer a gênese de um espetáculo implica em encontrar também suas correçóes, suas supressóes, os vazios deixados voluntariamente, os espaços em branco, como se pode fazer no estudo de um manuscrito. Contrariamente à gênese textual, a genética da encenação teatral normalmente não carrega o traço das suas correçóes nem das suas eliminações. Elas estão apenas na memória dos atores e criadores e nas gravaçóes de vídeo. Estão também nas anotaçôes dos observadores dos ensaios quando eles se dão ao trabalho de anotá-las. Mas elas não aparecem mais regularmente nas anotaçóes dos técnicos ou do diretor ou, ainda, do assistente. Ora, como no caso da filatelia, esses traços são como marcas d'água que aparecem por transparência e deixam zonas translúcidas através das quais passa a luz. Elas nos permitem ler o documento de uma outra maneira 5 .

Então é possível dizer que, se a genética dos textos deixa um grande espaço para o texto final, que não é realmente alterado por ela, mas esclarecido, a genética teatral trabalha sobre traços virtuais, às vezes de memória, frequentemente ausentes. Ela está relacionada à perda e pode conservar a falta, o esquecimento, o abandono.

\section{O Aleatório da Notaçáo}

Localizar a supressão dos traços é justamente um dos modos de trabalho sobre os processos de criação. Mas, como? Segundo quais princípios, segundo qual regra observar esses traços, sabendo que é impossível identificar tudo. Pois nem toda supressão é eloquente. Às vezes, algumas correçóes se devem à insuficiência de uma proposta, à sua ineficácia. Seria inútil repertoriá-las para lhes dar um significado, que nem todas têm necessariamente da mesma forma, na gênese do espetáculo.

Claro, é interessante, por exemplo, ouvir Mnouchkine dizer, sobre a criação de Les Atrides, que no início dos ensaios o palco era abarrotado de elementos (ela fala, nessa ocasiáo, de um chafariz no meio do palco), mas que pouco a pouco esses elementos, a partir da 
manipulação dos atores, são progressivamente eliminados do palco. Também é emocionante vê-la em ação, no filme Au Soleil même la nuit, em uma luta para equilibrar o espaço, procurando, após muitas tentativas, harmonizar a posição dos tapetes no espaço de cena. Sem dúvida, para o estudo genético, é inútil fazer o inventário completo dessas mudanças e basta lembrar dos detalhes importantes. Mas, é mais do que instrutivo poder constatar que, nessa elaboraçáo da obra, os muros continuam lá, ainda mais fortes, mais sólidos. Essas escolhas são ricas em significado, ao mesmo tempo para o espetáculo e para o modo de criação do Théâtre du Soleil. Isso significa que o campo de análise genético náo é apenas o campo dos documentos arquivados visíveis, mas, também, dos invisíveis, apagados, que apenas a memória ou a observação podem identificar. Assim, realizar uma análise genética consiste também em fazer surgir correçôes, supressões, aquilo que é considerado importante na genética dos textos, mas que, frequentemente, se encontra distante na análise da encenação teatral.

Diga-se novamente que, atualmente, nada nos permite listar, ou mesmo registrar essas supressōes, a não ser as gravações em vídeo que, eventualmente, um pesquisador poderia assistir integralmente, ou os ensaios que ele poderia assistir.

Acrescente-se ainda que, mesmo estando convencida da necessidade de fazer aparecer, como uma marca d'água, ou como um palimpsesto, as versões anteriores da obra, a escolha continua sendo um imperativo para o pesquisador. Ele deve eliminar algumas das suas observaçóes, fazendo com que sua análise genética dependa inteiramente de suas intuiçôes e de suas escolhas. $O$ aleatório, embora mais explícito, continua assim no núcleo do trabalho, um aleatório que depende do livre-arbítrio do pesquisador, da sua metodologia, de seus objetivos.

\section{Começos pouco Definidos}

Essa questáo coloca uma outra, muito importante. Uma questão sobre a delimitação do campo, se não dos processos de criação, pelo menos da genética e do que ela representa. Colocada de outra forma, a questão é saber o que faz parte de um estudo genético e, de maneira secundária, onde se situa o início da gênese, questão impossível, e sem dúvida um pouco retórica, mas que permite medir o horizonte extremamente amplo da área, hoje. 
Na introdução do seu livro, Genèses théâtrales, Almuth Grésillon, Marie-Madeleine Mervant-Roux e Dominique Budor (2010), reivindicam um campo bastante amplo para o estudo genético: a censura e as subvenções, as condiçóes de produção (no plano econômico, comercial, institucional), os documentos jurídicos e financeiros, as encomendas, as amostras, as notas fiscais, os contratos, as folhas de pagamento de salário, a quantidade e a duração dos ensaios, a agenda, as turnês e as eventuais retomadas do espetáculo, necessariamente, fariam parte dessa área de estudo.

Nessa amplificação existe, de forma completamente legítima e compreensível, já que todos esses aspectos intervêm necessariamente na obra, uma visão um pouco abrangente demais na nossa opinião, na qual tudo ou quase tudo faria parte da análise genética ${ }^{6}$.

Nossa reserva diante de uma amplificaçáo vasta demais dos estudos genéticos se baseia na observação de uma extrema diluição do campo de pesquisa nesse setor e ao fato de que, visto por esse ângulo muito inclusivo, a Genética Teatral se diferenciaria muito pouco das análises já existentes há muito tempo. De fato, os estudos econômicos, jurídicos, financeiros, dramatúrgicos ou das condiçôes de produçáo não são novos na área do teatro. Eles demarcam o campo da pesquisa há muitos anos, mesmo se a especificidade dos estudos genéticos seria de fazer dialogar esses elementos com o objetivo de explicar o processo de criação de uma obra. Mas tais afirmaçôes bastam para criar uma nova área de especialização? Deve ser considerado que talvez, sob esse ponto de vista, o campo da genética perca a sua relevância na tentativa de considerar tudo como uma contribuição à criação ${ }^{7}$, mesmo se a transversalidade e a interdisciplinaridade dessas exploraçóes sejam certamente inovadoras.

É por essa razão que me parece necessário, indispensável mesmo, operar uma distinção clara entre a análise genética no seu sentido mais geral e unificador e a análise dos processos de criação propriamente ditos, que estaria no núcleo do estudo genético da encenação teatral. A análise destes últimos se apoiaria, prioritariamente, na observação propriamente dita dos ensaios.

Efetivamente, é fundamental concentrar o campo de pesquisa nos processos de criação stricto sensu e focar a observação nos ensaios e nos documentos relacionados que levam à criação de um espetáculo, uma área cujo desenvolvimento é intimamente ligado ao trabalho dos artistas. Essas pesquisas requerem não apenas a presença nos ensaios, mas uma atenção constante à construção da obra. 
O que essas pesquisas refletem é o aumento do interesse dos pesquisadores pela fabricação dos espetáculos, um interesse que já tinha começado desde o final dos anos 1960, no momento em que os artistas de teatro abrem os bastidores e mostram como o fazer teatral é uma parte integrante do espetáculo. A fronteira entre o esboço e o espetáculo era assim diluída, as primeiras tentativas, esboços, preparativos, tornam-se, então, parte integrante de um interesse generalizado pela fabricação da obra, revelando-a ao espectador.

Pessoalmente, eu tenho tendência a privilegiar de maneira bastante próxima os processos de criaçâo, um campo de pesquisa que certamente tem uma história mais recente que a da genética no seu sentido mais amplo, um campo que ela parece querer adotar, mas que me parece necessário privilegiar. $\mathrm{O}$ surgimento desse interesse na esfera crítica está, evidentemente, ligado à evolução das formas cênicas contemporâneas, que se tornaram mais complexas, considerando inteiramente como criadores, ao lado do duo autor-diretor, é claro, os atores, mais do que nunca colaboradores da criação, mas também os cenógrafos e os criadores de som, vídeos, iluminação, os profissionais da informática, os técnicos (como, por exemplo, no complexo trabalho Zulu Time, de Robert Lepage, ou na sua tetralogia de Wagner no Metropolitan Opera de Nova Iorque; ver, também, o sutil espetáculo Is you me de Benoît Lachambre, criado em colaboração com Laurent Goldring, Hahn Rowe e Louise Lecavalier).

\section{Restringir a Extensão da Área}

Muitos elementos contribuem hoje para a disseminação do estudo dos processos de criação como um campo de pesquisa autônomo e podem ser identificados na própria evolução do teatro.

a) Por um lado, o fato de que os espetáculos sejam considerados atualmente como works in progress, mesmo se a palavra desapareceu dos cartazes e que seja normal que as obras tenham diferentes versóes com variantes, como fazem frequentemente Lepage ou Mouawad, Lemieux e Pilon, mas como faziam antes deles Wilson ou Sellars. Essa prática, estabelecida desde então, merece ser citada. Evidentemente, os espetáculos não são mais apresentados como work in progress, mas a ideia de que uma obra nunca é terminada e que ela evolui segundo o ritmo das suas diferentes apresentaçóes faz parte dos costumes. Essa prática favorece a promoção de estudos sobre os processos de mudanças e transformaçôes das obras. 
b) Junte-se a isso o fato de que muitos espetáculos, ou formas de dramaturgia, se constroem no palco, durante a apresentação; não apenas dramaturgias de palco, mas dramaturgias performativas como faz, por exemplo, a companhia TG Stan. Essa forma de escrita relaciona diretamente, e sem passar pela fase comum dos ensaios, o trabalho de reflexão e análise dos textos - um trabalho que antecede a verdadeira criaçáo em cena -, ao momento da apresentação. Tratar-se-ia quase de um trabalho de criaçáo ao vivo. O espetáculo é o processo. Torna-se difícil, assim, distinguir a obra em curso e a obra acabada.

c) Assim, não é surpreendente que muitas companhias tenham adotado estruturas nas quais a posição do diretor se transformou e náo se encontra mais no núcleo do processo cênico, ou mesmo, que ele tenha simplesmente desaparecido. Estaríamos assistindo a um desaparecimento do diretor, um século e meio depois do seu surgimento? A questáo é interessante em si mesma, mas, também, pelo que ela nos revela sobre os processos de criação. A observação do trabalho torna-se, assim, a observação dos múltiplos colaboradores de uma estrutura que se constrói e se desconstrói ao longo da criação, deixando o trabalho de análise certamente mais difícil, mas permitindo a observação da cena sob um ângulo variável, não polarizado pela personalidade de um diretor que centraliza a atenção.

De fato, é preciso constatar que, mesmo quando o lugar do diretor continua existindo, as pessoas que estão à sua volta - atores, criadores de som e vídeo, cenógrafos - têm papéis fundamentais na criação. O que seria de Robert Lepage ou de Marianne Weems sem as suas equipes de vídeo-artistas? Mnouchkine sem Jean-Jacques Lemêtre? Ivo van Hove sem seu cenógrafo, Jan Versweyveld. Alguns diretores dizem mesmo que os seus papéis se resumem hoje a um trabalho de montagem e organização das cenas (Markus Ohrn). Esse questionamento sobre o lugar do diretor é uma das mais importantes transformaçôes da nossa época. Ele é representado (ou talvez conduzido?) de forma mais intensa por algumas companhias flamengas (sobretudo TG Stan, mas, também, de Koe, em Berlim) cujo exemplo parece inspirar outros (Raoul Collectif).

d) Finalmente, uma dificuldade adicional na análise dos processos de criação: algumas companhias não ensaiam. TG Stan tornou essa maneira de trabalho o seu modo de fazer. Acompanhá-los em um trabalho sobre o processo de criação exige assim uma grande adaptação da parte do pesquisador. 
e) Em outro nível de observação, a moda dos remake ou dos reenactment (Abramovic, Wilson, The Living Theatre, Jan Fabre, Maguy Marin $)^{8}$ coloca uma questão interessante sobre os processos de criação. Assim, Einstein on the Beach, apresentado pela primeira vez em 1976, é retomado em 2011, L'empereur de la perte, de Jan Fabre, montado em 1996, é remontado em 2012 com um novo elenco, Parades and Changes, coreografia de Anne Halprin, criada em 1965, é retomada por Anne Collod em 2008 e em 2013 com o título de Parades and Changes, Replay in Action, e, finalmente, May be, de Maguy Marin, apresentado pela primeira vez em 1981, é retomado pela própria artista em 2012. Os diretores retomam todos os seus trabalhos e, de preferência, em série: diversas obras de Maguy Marin estão em Paris neste outono, assim como de Jan Fabre: seis de Fabre, seis de Maguy Marin, quatro de Pierre Rigal. Os diretores se baseiam nos arquivos, nas gravaçóes, mas eles retomam, adaptam, modificam. Evidentemente, analisar essas modificaçôes é interessante, mas é ainda mais interessante o fato de poder acompanhar os ensaios e o trabalho de modificação feito com os atores?

f) Finalmente, na outra ponta do caminho, é possível que a presença do espectador seja uma parte constitutiva do processo de criação da obra, o espectador sendo uma parte indispensável da obra. Sem ele, o espetáculo não existe, não apenas no sentido ao qual Peter Brook se referia, falando da necessidade de um ator sobre um espaço cênico e de um espectador que o observe para que haja teatro, mas no sentido que o espectador ativa o espetáculo e o faz existir. Sem ele, não há nada para se ver. Eu penso na companhia Blast Theory, que faz o espectador subir em uma bicicleta (Rider Spoke) ou seguir um avatar que ele acompanha pela tela do seu Ipod ou Ipad (A Machine to See with, Can you See Me Now). Sem essa ativação, o espetáculo não acontece. Não apenas a obra precisa do público, mas ela náo existiria sem o espectador que faz com que ela aconteça. Evidentemente, trata-se de uma experiência limite, mas que, no entanto, existe e que coloca questóes interessantes à análise dos processos de criação. Como relatar essas experiências, não somente no plano da gestação do projeto, mas, mais ainda, quando a criaçáo transborda e acontece no momento da apresentação? A problemática é empolgante.

Existe assim, de uma parte, uma visão purista, de Gay McCauley (2008) que, muito antes de todo mundo, havia realizado um trabalho de leitura e decodificação sistemática dos ensaios ${ }^{10}$. Essa é a minha visão, mas, também, a de todos estes jovens pesquisadores 
que acompanham os ensaios e colocam em evidência os processos de criaçáo. Entram nessa categoria os trabalhos de Fanny Le Borgne sobre Kentridge, Giulio Boato sobre Jan Fabre ${ }^{11}$, que podem ser conhecidos neste número da revista, assim como os trabalhos de G. Girot e L. Guillot sobre Lauwers. O resultado dessas pesquisas é revelador do trabalho real da criação.

De outra parte, existe uma visão abrangente e que aumenta o campo da genética a todo processo. É a visão de muitos pesquisadores, sobretudo franceses (Gresillon, Mervant-Roux, Budor, Proust).

Tanto em um caso quanto no outro, fica claro que essa inclinação em direção ao processo é o efeito de uma evolução quase natural de nossas práticas de pesquisadores. Nosso olhar mudou, é um fato, e nossa época se interessa profundamente pelos modos de surgimento da criação. Desse interesse nascem as pesquisas genéticas e sobre os processos de criação das quais estamos falando. No entanto, eu continuo convencida de que o estudo dos processos de criaçáo propriamente ditos, estudos feitos em campo, é, na minha opinião, o caminho privilegiado para se introduzir na criação e acompanhar o percurso de um artista.

De maneira ainda mais importante, me parece que falta alguma coisa nos estudos genéticos muito amplos. Porque, nos processos de criação, não se trata somente de compreender melhor a abordagem de um artista e de uma obra, mas existe, além disso, o interesse em se compreender os movimentos de criação, como a prática funciona e como os artistas pensam a sua arte. Não se trata somente de reconstruir os sistemas de pensamento e de criação a partir de metodologias já comprovadas. Trata-se fundamentalmente de colocar-se em estado de aprendizagem, no qual o pesquisador renuncia a seus pontos de referência habituais, a seus modos de conhecimento, tentando compreender e funcionar de outra forma. Postura idealista, sem dúvida. Provavelmente insustentável. No entanto, é uma postura que tenta ser assumida no mundo anglo-saxônico, com o nome de practice as research ou art-based research, duas áreas de investigação que náo abrangem as mesmas realidades, mas que mereceriam ser expostas. 


\section{Notas}

${ }^{1}$ Os estudos nesses dois campos são numerosos. Citemos, a título de exemplo, sem fazer distinção, os trabalhos de Thomasseau; Grésillon; Léger (2005), Proust (2006), Cvekic; De Keersmaeker (2012). Dito isso, muitos trabalhos anteriores já tinham sido feitos de maneira diferente: McAuley (2008); Mitter (1992), Letzercole (1992) Toporkov (2001). Mas, também, na França, Banu (1997) reeditado por Actes-Sud em uma versão revisada (2005), assim como Féral (2008).

${ }^{2}$ Ver as anotaçóes de Yves Godin, cocriador com Pascal Rambert do espetáculo Memento Mori (Gennevilliers, março de 2013) e colaborador artístico, dispositivo cenográfico e iluminação. Essas anotações constavam no programa distribuído aos espectadores. Memento Mori último dia de ensaio. Medir o caminho percorrido desde as primeiras conversas com Pascal há um ano. Passar pela peneira do trabalho e da experiência no palco, o que resta das primeiras intençóes, das primeiras instruçóes dadas? Ao que Memento Mori dá o seu nome, hoje. Provavelmente simplesmente a uma passagem, instável. Uma passagem incerta entre a matéria e o imaterial, corpo se desmaterializando, halos famélicos e móveis, luz ausente quase sólida, compacta, apreensível. Com os cinco performers, nessa forma em escrita instantânea, nós fabricamos visões, mais do que imagens. Nossas regras são mínimas e complexas, passam muito pouco pela linguagem. Memento Mori se construiu com base em dramaturgias personalizadas. Radicalizar ainda mais a forma (Godin, 2013).

${ }^{3}$ Sobre esse assunto, ver o que diz também Jean-Loup Rivière: " $\mathrm{O}$ arquivo de teatro é essencialmente lacunar. Sendo que, sem dúvida, o arquivo de uma obra escrita ou pintada é um acréscimo, o arquivo de teatro é o resultado de uma subtração. Ele perde necessariamente o seu objeto, ele é a sua ausência, sendo que o arquivo de uma obra escrita, ao contrário, a envolve, a cobre, a intensifica [...] Face ao arquivo de teatro, temos um 'de menos' e a partir desse momento, é necessário imaginar um todo que, é claro, é absolutamente diferente e definitivamente inacessível" (Rivière, 2010, p. 4).

${ }^{4}$ Marleau foi interrogado sobre esse ponto.

${ }^{5}$ Eu gostaria de lembrar que, para mim, esse interesse pelos processos de criação nasceu de um choque, ocorrido em 1995, durante a visita da Schaubühne a Toronto e de um Master Class, conduzido por Andrea Breth, na época diretora dessa importante instituição. Ela havia apresentado uma cena de $A$ Gaivota (a cena na qual Treplev e Nina se separam, e que precede o suicídio de Treplev, quando ele compreende que Nina, mesmo infeliz, mesmo abandonada, nunca será sua). A mesma cena, vista dois anos mais tarde em Berlim, apresentava escolhas artísticas completamente contrárias ao que havia sido construído dois anos antes. De fato, no primeiro caso, os atores estavam próximos a ponto de poderem se tocar: Treplev sentado na ponta de um divã sobre o qual Macha estava deitada, segurava forte a sua mão; no segundo caso, na versão final, dois anos mais tarde, o diálogo entre os dois personagens se desenvolvia à distância, separado por toda a extensáo do palco. Andrea Breth tinha restituído a distância entre os dois personagens de maneira ao mesmo tempo metonímica e metafórica, expressando assim o amor impossível entre eles. Pareceu-me, na época, que a eliminação de algumas escolhas no jogo ou na cenografia, se pudessem ser estudadas, diria tanto sobre o processo artístico de um artista quanto os elementos que tinham sido mantidos e relacionados no palco.

${ }^{6}$ Evidentemente que qualquer fator que tenha influência sobre um espetáculo pode fazer parte de um estudo genético se se tratar de um elemento importante. Assim, é fácil 
compreender que o preço dos tecidos pode influir de forma significativa na escolha dos figurinos e, portanto, na estética do conjunto, mas é realmente necessário classificar essas pesquisas como genéticas? $\mathrm{O}$ mesmo acontece com as condiçóes dos ensaios, que variam de país para país e que, necessariamente, tem suas consequências sobre a gênese de um espetáculo (planejamentos aleatórios, desistências, ensaios fragmentados, atores trabalhando em pequenos grupos nas cenas divididas). Da mesma forma, as condiçóes de instalação no espaço de apresentação, o pouco tempo que os atores e os criadores têm para adaptar o espaço de ensaios ao palco, são fatores importantes que influenciam os processos de maneira incontestável.

${ }^{7}$ A questão pode parecer inútil ou sem importância, mas ela esconde uma interrogação real, sincera, com a qual nós nos confrontamos regularmente no Grupo de Trabalho que eu criei em 2004 na FIRT - Federação Internacional de Pesquisa em Teatro, sobre os processos de criação (e que eu codirijo há alguns anos com Sophie Proust). De fato, a cada ano chegam até nós propostas sobre assuntos que podem ser considerados um pouco periféricos às questôes da genética: a música como princípio de estrutura do universo de criação de um diretor, a memória individual como base de criação de obras sobre a ditadura na América Latina; o direito de autor, o regime econômico que domina os ensaios; as Flash mobs como lugar de ressurgimento das comunidades de criação. Mesmo aceitas no Grupo de Trabalho, nem sempre nós nos convencemos de que essas propostas se tratem realmente de genética, ainda que as conclusóes dos pesquisadores destinem-se a mostrar sistematicamente a influência desses elementos sobre a criação de uma obra, prova de que seria conveniente criar uma definiçáo rigorosa.

${ }^{8}$ Einstein on the Beach, Apocalype Now, Antigone.

${ }^{9}$ Ver de maneira mais precisa o acompanhamento do processo dessas modificaçóes, como o fez Giulio Boato, observando a retomada do espetáculo de Jan Fabre, em sua dissertaçáo de mestrado (2012).

${ }^{10}$ Para realizar essa tarefa, ela chegou a criar na Universidade de Sydney uma estrutura que permitia aos professores e aos estudantes acompanhar os trabalhos de companhias em residência, especialmente convidadas, e cujos contratos estabeleciam que elas poderiam ocupar espaços da universidade em troca de um livre acesso dos estudantes aos ensaios.

${ }^{11}$ Ver os textos neste número.

\section{Referências}

BANU, Georges (Org.). Les Répétitions Un Siècle de Mise en Scène. De Stanislavski a Bob Wilson. Alternatives Théâtrales, Bruxelas, n. 52-53-54, 1997.

BOATO, Giulio. Jan Fabre: la realtà della finzione, tra teatro e performance. 2012. Dissertação (Mestrado em Performing Studies) - Université de Bologne, Bologne, 2012. (orientação de Luk van den Dries).

CVEJIĆ, Bojana; DE KEERSMAEKER, Anne Teresa. Carnets d'une Chorégraphe: fase, Rosas danst Rosas, Elena's Aria, Bartók, Mercatorfonds e Rosas. Maio de 2012. (com 4 DVD's em inglês).

DE BIASI, Pierre-Marc. La Génétique des Textes. Paris: Nathan Université, 2000. (Coleção 128). (Reedição em Hatier, 2005).

FÉRAL, Josette (Org.). Genetics of Performance. Theatre Research International, Cambridge, Cambridge University Press, v. 33, n. 3, out. 2008. 
FITZPATRICK, Tim; CARD, Amanda; PEARSON, Justine Shih (Org.). About Performance. Sydney: University of Sydney, 2002-2013.

GODIN, Yves Godin. Programme. Paris, Gennevilliers, 25 jan. 2013.

GRÉSILLON, Almuth; MERVANT-ROUX, Marie-Madeleine; BUDOR, Dominique. Pour une Génétique Théâtrale: prémisses et enjeux. In: GRÉSILLON, Almuth; MERVANT-ROUX, Marie-Madeleine; BUDOR, Dominique (Org.). Genèses Théâtrales. Paris: CNRS Éditions, 2010. P. 5-23.

LÉGER, Nathalie; GRÉSILLON, Almuth (Org.). Genesis (Manuscrits, Recherche, Invention), Paris, n. 26 (Théâtre), 2005.

LETZERCOLE, Susan. Directors in Rehearsal, a Hidden World. London: Routledge, 1992.

MCAULEY, Gay. Not Magic but Work: rehearsal and the production of meaning. In: FÉRAL, Josette (Org.). Genetics of Performance. Theatre Research International, Cambridge, Cambridge University Press, v. 33, n. 3, p. 276-288, out. 2008.

MITTER, Shommit. Systems of Rehearsal: Stanislavky, Brecht, Grotowski and Brook. London: Routledge, 1992.

PROUST, Sophie. La Direction d'Acteurs dans la Mise en Scène Théâtrale Contemporaine. Montpellier: L'Entretemps, 2006.

RIVIĖRE, Jean-Loup. La Lettre de l'IMEC (Institut Mémoires de l'Edition Contemporaine), Abbaye d'Ardenne, Saint-Germain-la Blanche-Herbe, n. 11, primavera de 2010. THOMASSEAU, Jean-Marie Thomasseau; GRÉSILLON, Almuth. Scènes de Genèses Théâtrales. Genesis (Manuscrits, Recherche, Invention), Paris, n. 26 (Théâtre), p. 19-34, 2005.

TOPORKOV, Vasili. Stanislavski in Rehearsal. London: Methuen, 2001.

YANDL, Andreas. En Quête d'une Vérité: analyse herméneutique de la genèse d'Urfaust, tragédie subjective: mise en scène de Denis Marleau, Théâtre Ubu, Montréal. 2001. Dissertação (Mestrado em Teatro) - École Supérieure de Théâtre, Universidade do Québec, Montréal, 2001.

Josette Féral é professora na Université Paris 3 La Sorbonne Nouvelle, na França. Foi professora na Université de Montreal em Quebec, no Canadá. Foi presidente da FIRT - Federação Internacional pela Pesquisa em Teatro. É autora de inúmeras publicaçóes, sendo uma das pioneiras da Genética Teatral. Publicou livros como Théorie et pratique: au-delà des limites (2011), Mise en scène et jeu de l'acteur, tomos 1, 2 e 3 (1997, 1998, 2007), Trajectoires du Soleil (1998), Rencontres avec Ariane Mnouchkine (1995) e La culture contre l'art (1991).

E-mail: josette.feral@gmail.com

Traduzido do original em francês por André Mubarack. Revisado por Gilberto Icle.

Recebido em 20 de fevereiro de 2013 Aprovado em 20 de abril de 2013 